\title{
Triple Bottom Line: Evidence from Aviation Sector
}

\author{
Isha Gupta \\ Research Scholar \\ Amity University, Noida \\ Uttar Pradesh, India \\ Email: ishagupta74@gmail.com \\ Nandita Mishra \\ Associate Professor \\ BIMTECH, Greater Noida \\ Uttar Pradesh, India \\ Email: saanvinandita@gmail.com \\ Deepak Tandon \\ Professor \\ International Management Institute, New Delhi \\ India \\ Email: deepaktandon@imi.edu
}

Received September, 2019; Accepted January, 2020

\begin{abstract}
The COVID-19 has spread with alarming speed bringing the global economy to a stand-still. As countries have imposed tight restrictions, the aviation industry is severely hit and its revenues sorely plummeted. The study aims to analyze the impact of Covid-19 on the aviation industry. Its main purpose is to alleviate the pandemic effect by applying the Triple Bottom Line (TBL) approach. TBL mainly addresses sustainability and focuses on three dimensions: people, planet, and performance. The aviation industry can sustain its revenues by adopting disruptive and innovative strategies that can counteract pollution effect (planet scale). Furthermore, it should urgently integrate artificial intelligence and machine learning in its booking system (people scale) to compensate for ongoing travel cancellations, delay, and headcounts reduction. To regain customers' confidence, and boost its performance, the aviation industry should apply innovative plans such as electronic waivers, free cancellation, no-fee itinerary change.
\end{abstract}

Keywords: COVID 19; Aviation Industry; Sustainability; Triple Bottom Line (TBL).

Type: Research paper

This work is licensed under a Creative Commons Attribution 4.0 International License.

DOI: 10.51325/ijbeg.v3i1.32

\section{Introduction}

In the last $20^{\text {th }}$ century, sustainability has already become a very thought-provoking theme in the world that affects all industries around the globe. A powerful continuous change has been evident from the last few years. This affects all markets, some of which are less affected, while some more. Many corporations manipulate sustainability to not only reflect on their credibility, but also to strengthen processes, drive for growth and to create value for their businesses. This transition involves the National Action Plan on Climate Change (NAPCC) in 2008, which affects legal stipulations, as well as each individual's overall attitude. One of the first sector that comes to mind when considering of unsustainable industries is the aviation industry, due to its high fuel consumption and massive emissions from greenhouse gases. Aviation impacts the environment in several ways: people who live near airports are subjected to aircraft noise; streams, rivers, and 
wetlands can be subjected by storm water runoff to pollutants released from airports; and aircraft engines release pollution into the environment. It outlines commercial aviationrelated emissions and the welfare and health consequences that could result through aviation emissions that not only exacerbate air pollution, as well as the ecological climate.

During these challenging times of coronavirus outbreak, when each sector is impacted by this unprecedented crisis and the functioning of almost every industry has been derailed. There is a need to build an environment that is sustainable and well-equipped to confront against imminent crises. The repercussions of the round-the-clock pandemic COVID 19 on the aviation sector will surpass both the Icelandic volcano crisis of 2010 and the terrorist attacks of $9 / 11$, along with the airlines are struggling to deal with the economic realities of the crisis and projecting new normal strategies. Earlier, business success is assessed by only one bottom line, i.e., the financial one. Nowadays, demand has been increased to report the impact of business on the environment and the community. Therefore, there is a need for the Triple Bottom Line (TBL) concept. In finance, the bottom line of the business usually means its earnings. Elkington's Triple Bottom Line structure promotes the concept of sustainability in corporate practises, in which corporations look beyond profits to address social and environmental challenges in order to calculate the full cost of doing business. The Triple Bottom Line strategy helps to recognize the position of business in the current economy and its potential to succeed in the future. Corporate sustainability analyses entrepreneurship is potential to be forever in business based on environmental effects, community relationship and economic contribution. In reality, all three factors have a major role to play in deciding whether business can remain indefinitely and produce profit- no single bottom line in business alone would survive (Sustainability Management System: The Triple Bottom Line, Chamberlain, 2020).

Triple Bottom Line $=$ Profit + People + Planet

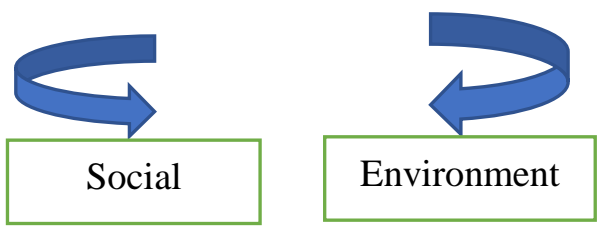

Figure 1: Structure of Triple Bottom Line Source: Author's Own Compilation

The figure shows the elements of Triple Bottom Line i.e., profit, people and planet. In accordance with framework of TBL theory, companies work concomitantly on these three bottom Lines. Profit is the conventional measure of profit and loss; People measures socially progressive aspect of business in the past and Planet measures how company has become an environmental conscious.

\section{Triple Bottom Line (TBL) and Aviation Industry}

To prepare successful business strategies for government infrastructure spending, the use of the Triple Bottom Line analysis is becoming critical. Its global coverage and use of primary and secondary research are especially helpful for airports to illustrate their influence and importance, as well as to promote complementary industries in the 
communities and regions surrounding them. A TBL offers a framework to indicate adequately that the necessary infrastructure project would have an even-reaching effect that makes the initiative profitable.

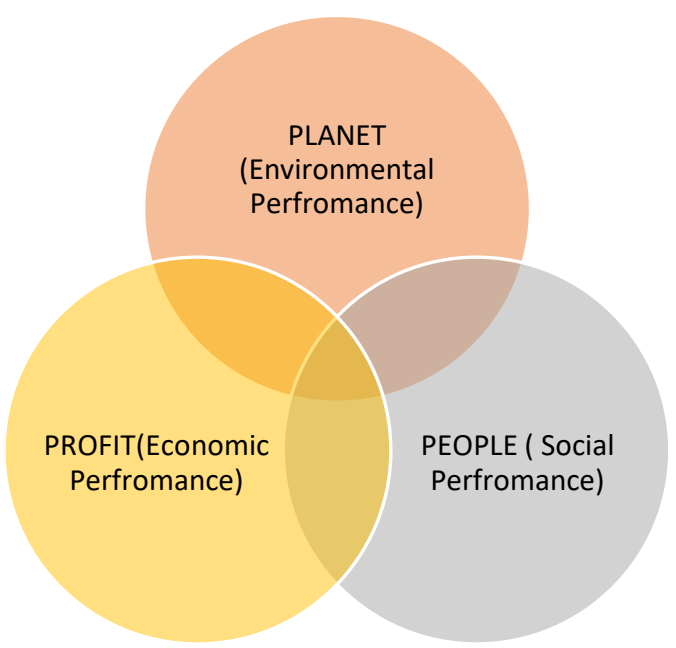

Figure 2: Triple Bottom Line component with its performance-measuring variable. Source: Southwest Airlines and Triple Bottom Line ${ }^{1}$

\subsection{Economic Analysis:}

As development initiatives are geared at projects that will see immediate job growth, economic benefits are perhaps the most significant component of the TBL report. Since airport infrastructure projects often require a substantial construction time, such as runway extensions, they are helpful in showing the immediate growth of employment and incomes. In addition, airports have the potential to generate significant important trade sectors such as tourism and commerce, which are both often government-targeted sectors for development. Projects that encourage traffic growth at an airport may also be related to funding for those industries. Validating an impact of job growth on outside sectors offers a strategic advantage for ventures seeking funding. Financial impacts are also part of the economic study in the TBL.

Even though this could provide more theoretical indicators including the opportunity cost for use of land, the receipts of tax of the employment generated by use of land are a significant way to explain the "repayment" of funding.

\subsection{Environmental Analysis}

The analysis of the TBL must also exemplify that, beyond the construction phase, no new negative environmental effects would result from the planned project relative to the status quo. Developments in projects designed to integrate sustainable practises and provides a benefit to projects that are endeavouring funding. Because this is going forward, initiatives that encourage reduced environmental impacts are becoming criteria for some programmes for financing infrastructure. In the case of business, it is important to

\footnotetext{
1 Retrieved from https://blogs.ubc.ca/annicechang/2014/11/05/southwest-airlines-and-triple-bottom-line/ on $19 / 09 / 2020$.
} 
demonstrate that sufficient mitigation measures undertaken to ensure that the environment for the actual construction of the project is minimally affected.

\subsection{Social Analysis}

In most current business cases, social benefits are generally not needed, however, being able to illustrate the advantages provides the business case with tremendous value. Demonstrating social benefits for airports can range from observable, quantitative impacts such as noise effect mitigation to qualitative impacts such as neighbourhood impacts.

In 2008, the Federal Government of Canada issued a study on the full transport costs. As required in proposed business cases, Triple Bottom Line (TBL) research based on economic, social, and environmental accounts has shifted both the U.S. and Canadian governments. This is the accounting approach that can be used for government funding in case of business (Triple Bottom Line Analysis and Justifying Airport Infrastructure Projects, Shover, 2010).

This chapter will describe the term sustainability and clarify what it consists of under the Triple Bottom Line Model. In addition, a closer look will be taken into the airline industry to examine the threats and future opportunities faced by the industry during this major transition. Although emphasizing on the research question 'the degree to which the airline industry is adapting to the sustainable change'. This will help to gain a better understanding of the practical implementation as well as elaborate theoretically.

\section{The association between Sustainability and Triple Bottom Line}

The major problem found from a systematic analysis of the literature undertaken showed an incoherent use of the word sustainability. Thus, to incorporate a detailed understanding of the issue of this chapter the word sustainability must be defined first. Many scientists attempt to describe sustainability in various ways, but one general definition of it is very difficult to find (Patlins, 2017; Alareeni, 2018). Sustainability is an approach that is embraced when building skills that can help concentrate on the future in order to meet current requirements. In other words, to fulfil their own needs, present and future generations should have equal opportunities (Chabowski et al., 2011). In order to dive deeper into understanding sustainability, it must be pointed out that there is a model which forms the basis for defining the concept. The Triple Bottom Line Model is this model (Elkington, 1998). It is a system that measures the degree of sustainability (within a business) premised on the three pillars - environmental, social and economic (Barbier, 1987).

These concepts are central to the applicability of sustainability to three facets of life: financial issues or economic issues, environmental sustainability, and individual human well-being and society: the sustainability line of triple bottom. This means improving the economic and social quality of life while mitigating the impact of the climate on the balancing ability of nature. In this sense, optimum solutions to any kind of issue will yield long-term benefits in all three parameters (Arowoshegbe, 2018).

In order to promote the sustainability agenda, John Elkington (1994), proposed novel term known as a 'triple bottom line (TBL). The TBL can be defined as, "The simultaneous promotion of economic growth, environmental sustainability, and social justice requires 
sustainable development". Instead of a single financial bottom line, businesses aiming for sustainability must contend against the triple bottom line. (Elkington, 1998).

Mintz (2011) agrees that while the commitment of managers to their organisations' environmental and social effects has been rise but normative accounting comparable to those in financial accounting is not easy to build. He concludes that key performance measures (KPIs) or quantitative metrics must be established by organisations linked to their own roles, goals and stakeholder expectations. The study (Adams et al.,2004) concluded that no accounting principles or metrics are universally or commonly accepted to assess environmental or social performance.

For companies that are wary of valuing social / environmental sustainability equally with economic efficiency, Southwest Airlines is the perfect example. Its legacy will not simply rest on becoming a means of transport, but with its points of difference that win. The business model of Southwest Airlines shows that businesses that make an effort to communicate with the world and the people will not hamper profitability but rather catalyse it. There are few studies on the effect of the Triple Bottom Line on the aviation industry. This definition in Aviation Industry of India is at its infancy stage. Thus, examining this effect is of utmost importance, hence the focus of this chapter is on bridging this research gap.

\section{Sustainability in Aviation}

The aviation industry is an important part of tourism, as it forms an integral part of transportation systems (Bonser, 2019). Aviation is fundamentally global since it is the key communication of most countries around the world. Even the smallest corners on earth were reachable in the fastest way. Although 'the aviation industry is relatively small, it has a disproportionately large effect on the climate system. The environmental effect of aviation is characterised by negativity in the review of SDG. This is because huge quantities of greenhouse gases are released which contribute to climate change and global warming (Richter, 2020. A rise in public opinion that aviation is bad, and green is healthy has been foreseen as society observed improved air quality and birdsong resonating during the lockdown in gardens.

Airports are critical gateways act as a guardian that can help to avoid the spread of viruses into the wider population. As IATA (2020) has figured out, travel bans will not stop the illness. However, if any outbreak occurs, all aviation players, especially airlines, should review their operation and enforce appropriate guidelines that are applicable to the disease in accordance with to standards established by ICAO. As airlines continue to adapt to overwhelming new challenges, they remain focused on preserving customer interest and paving the way for rapid recovery once the operations return to complete. Yet innovation also expands during periods of restriction to satisfy both current and new needs. With lessons gathered from how the consumer journey was resistance-tested, airlines will continue the creativity and change triggered by the pandemic. This innovation could set the stage for travelling in the future. Thus, the policy formulated by Ministry of Civil Aviation, the Government of India the National Green Aviation policy will help in order to recover quickly and maximise revenues after COVID 19 in order to steer the company in right direction. 


\subsection{The National Green Aviation Policy}

The Department of Civil Aviation of the Government of India is pledged to the inclusive and sustainable growth of the civil aviation sector in the country, and at the same time reducing its adverse effects on the environment. This White Paper sets out a policy plan to tackle the aviation industry's major environmental challenges. The policy vision is to encourage, foster and strengthen all integrated, sustainable and green aviation growth in India, while the policy goal is to ensure safe and secure aviation flights to different regions of India and the world by mitigating the negative impacts on the environment of civil aviation operations. The program would support the contribution of India to the following global regulatory and legislative approaches:

- The vision, mission and ambitious priorities of the International Civil Aviation Organization (ICAO) towards environmental protection.

- United Nations Sustainable Development Goals (SDGs), 2030; and

- India's Nationally Defined Planned Contributions (INDC) under the United Nations Framework Convention on Climate Change (UNFCCC)-the objective of the Paris Civil Aviation Ministry Agreement to achieve Sustainable Aviation as outlined in the 2016 National Civil Aviation Policy.

The Sustainable Aviation Agenda intends to build environmental policy issues related to the environmental management system, aviation engineering design, infrastructure improvement initiatives, noise reduction, global warming and greenhouse gases, local air pollution, conservation of energy and resources, and solar and other renewable energy.

\section{TBL: An Evidence from Southwest Airlines}

Southwest Airlines, headquartered in Dallas, keeps segregating itself among other flyers in its 43rd year of operation, with outstanding customer service provided to more than 100 million customers annually by more than 45,000 employees. Based on the latest available US information. Transportation department, in terms of boarding domestic voyagers, Southwest is the largest airline in the country. One of the world's most honoured airlines is Southwest. The award-winning One Study by Southwest Airlines complies to the Global Reporting Initiative (GRI) and includes parallel CDP (formerly Carbon Disclosure Project) research that explores proactive environmental risk management, concentrating on greenhouse gas emissions and policies for climate change. Under GRI guidelines, the B+ rank has been achieved by the 2013 One Report. Southwest remains a leader within its business, among others, the only one of the multitudes of U.S. corporations that issue an integrated corporate sustainability report. The intriguing statistics from the report One Study for 2013 include:

PERFORMANCE: In 2013, Southwest Airlines posted $\$ 17.7$ billion record in sales, amplified by higher returns and an 80.1 percent load factor. The Business reached its goal to boost cost efficiency through a combination of stable fuel prices and robust cost management initiatives.

PEOPLE: With more than 144,000 hours, Southwest Airlines employees volunteered, that is ample time to travel 52,364 times between San Juan Luis Munoz Marin International Airport and Orlando International Airport, one of the first relatively close-international routes in Southwest. 
PLANET: They ended up saving approximately 60 million barrels of plane fuel by constantly improving our fuel mileage between 2012, and 2013 equivalent to nearly 9,900 round-trip flights between Las Vegas (LAS) and Chicago Midway (MDW), thus achieving a complete reduction in greenhouse gas emissions at the same time.

Southwest Airlines is aligned with a triple bottom line approach that defines success and efficiency, the appreciation of employees and the communities, and commitment to the earth and efficiency. These elements are interconnected and mutually related. Fuel production programmes minimise costs, while mitigating the effect on the environment. Likewise, investments in the communities where Southwest flies help make them better places to work, visit and live. Indubitably, without 46,000 enthusiastic workers none of that will happen. The airlines are committed to developing a work-safe atmosphere in which workers have opportunities to build a career.

Due to its commitment towards sustainability, the airlines have launched Evolve campaign that includes the redesigning of all aircrafts. By replacing leather seats and other interior materials with environmentally friendly and durable products, the airlines have reduced the weight of each aircraft by over 600 pounds. This revealed a total of approx. 43 acres (nearly 80,000 leather seat coverings) of used leather. The company can simply abandon this leather quantity, whereas airline choose to find a new way of reusing it. The leather upcycling method or the conversion of waste materials to higher-value new materials or products provided Southwest with a wonderful idea to build a huge-scale leather effect. By upcycling, Southwest wants the items to have a positive impact on people, to support the individuals who create them, to address problems facing the people where they are created, and to develop new social enterprises so that the results of the project live longer than a single donation.

\section{Conclusions}

In this review, the interface between 'Sustainability' and 'Triple bottom line' (TBL) is explored as two substitute words used interchangeably in literature. As the prevalence of Triple Bottom Line Reporting increases and more rivals from different industries choose to address the social and environmental problems at work, it is imperative to improve the criteria by which companies operate to meet higher requirements. The quest to preserve all the resources available to future generations while using just enough to survive today must be part of the evolutionary process towards sustainability. These operating market practises can never be static with new innovations that are being introduced and numerous problems that will be uncovered.

TBL reporting has three dimensions, as previously stated: persons, the world, and benefit. The social dimension includes the influence that the organisation has on its workforce and the social structure within its society. If businesses look at the environmental factor, they really have to consider at the quantitative and qualitative effects they have on with the regional, global, and international resources. Last, although not only, economic component, financial performance of the company, the flow of capital and its economic participation in society.

The adoption of Triple Bottom Line by Southwest Airline distinguished it from other airline and made it leading airline of US. In the COVID-19 pandemic, Southwest Airlines is adopting unique framework for administering its ability to be different from others. Over the next few weeks, the company's capacity cuts are not as severe as those of its 
rivals, a move motivated by its conclusion that it is easier to take resources out of the system than to put supply back into its schedule. The airline is trying to retain as many destinations as possible throughout the situation, and most of those destinations stay unchanged at this stage. But Southwest is insisting that if demand continues to be small, it will take more resources out of its operations. Southwest is also partnering with other airlines to ensure that travellers feel relaxed flying over the next few weeks and months, including capping bookings on an aircraft so that travellers can practise social distancing. But, at some stage, airlines need to strike a balance between distancing themselves from society and ensuring air travel affordability (COVID-19: Southwest Airlines: Nuanced Crisis Management, CAA, 2020).

\section{Suggestions}

The COVID-19 pandemic, inevitably, pushed most flight to a halt, causing considerable turmoil in the airline industry. As airlines keep evolving to overwhelming new challenges, they remain focused on preserving customer loyalty and paving the way for rapid recovery once completely returned operations. The airlines need to indentify and prioritise to respond to today's challenge and business objective post-COVID-19. In certain industries, technological creativity is already breaking limits with no triggers, with an added advantage for the world. The best example of this is that social distancing initiatives have triggered a technical revolution; virtual interactions and meetings are now intending to spread globally. Aviation is a resilient industry that has recouped from preceding shocks and the path to the Triple Bottom Line would hasten critical change.

The airline industry should focus on prioritizing digital experience through all (desktop, mobile app and mobile web), rather focusing on one channel, as it is important to consider the role of each in the client's journey. Travelers search for initial inspiration and knowledge on the smartphone, and then many switches to a laptop to pick and pay for seats or baggage choices. This makes it important to connect mobile and desktop to drive seamless bookings (A Post-COVID-19 Strategy for Airline Passenger Experience Plan, 2020).

The airlines need to take help from analytics, artificial intelligence and machine learning to meet customer expectations that are transformed after pandemic. Digital experiences are becoming more like a human interaction. This can be developed from COVID-19 into a real-life example. Many travellers' trips were either delayed or cancelled during the pandemic. If consumer perceptions about travel change, airlines may take advantage of past travel interests. They can check for similar flight schedule options or offer alternatives, taking into account the COVID-19 restrictions and customer behaviour).

Fear and uncertainty are affecting future travel bookings. Airlines should be much more welcoming and versatile than usual and, to a greater degree, tend to be. Waiving, adjust and cancel fees and allowing convenient rebooking would help boost brand perception, feedback of customers and eliminate any confusion for those who wish to book future travel (COVID-19 and Airlines-Start Planning recovery now, Hiotis et al, 2020).

Concisely, as it is unknown how long this will last, but eventual regeneration and bounceback will occur. Although the emphasis should be on the present, and plan should be towards recovery form the ground level. This will include the recalibration of revenue control systems, the re-examination of price points and the re-establishment of price and marketing strategies to re-engage clients with the great benefits and value of travel for business or leisure purposes. 


\section{References}

Adams, C.A. (2004). The ethical, social and environmental reporting-performance portrayal gap, Accounting, Auditing \& Accountability Journal, 17(5), 731-757. https://doi.org/10.1108/09513570410567791

Air Cargo Essential to Fight Against COVID-19. IATA. (2020, 18 March). Retrieved from (https:/www.iata.org/en/pressroom/pr/2020-03-16-01/) on 20 September 2020.

Arowoshegbe, A. O., \& Emmanuel, U. (2016). Sustainability and triple bottom line: An overview of two interrelated concepts. Igbinedion University Journal of Accounting, 2(16), 88-126.

Barbier, E. B. (1987). The concept of sustainable economic development. Environmental conservation, 14(2), 101-110. https://doi.org/10.1017/S0376892900011449

Bonser, M. (2019). Global aviation system: Towards sustainable development. International Journal of Aviation, Aeronautics, and Aerospace, 6(3). Retrieved from https://commons.erau.edu/ijaaa/vol6/iss3/8. https://doi.org/10.15394/ijaaa.2019.1356

Chabowski, B. R., Mena, J. A., \& Gonzalez-Padron, T. L. (2011). The structure of sustainability research in marketing, 1958-2008: a basis for future research opportunities. Journal of the Academy of Marketing Science,39(1), 55-70. https://doi.org/10.1007/s11747-010-0212-7

Chamberlain, A. (2020). Sustainability Management System: The Triple Bottom Line, Retrieved from (https://www.era-environmental.com/blog/sustainabilitymanagement-triple-bottom-line) on 18 September 2020.

COVID-19: Southwest Airlines: Nuanced Crisis Management. CAPA. (2020, May 25). Retrieved from (https://centreforaviation.com/analysis/reports/covid-19-southwestairlines-nuanced-crisis-management-523479) on 20 September 2020.

Dunbar, M. F. (2015, January 3). Southwest Is Still America's Great Airline. Retrieved from (https://consciouscompanymedia.com/sustainable-business/southwest-is-stillamericas-greatest-airline/) on 18 September 2020.

Economics Impact of COVID-19 on Civil Aviation, ICAO (2020). Retrieved on (https:/www.icao.int/sustainability/Pages/Economic-Impacts-of-COVID-19.aspx) on 19September 2020.

Elkington, J. (1994). Towards the sustainable corporation: Win-win-win business strategies for sustainable development. California management review, 36(2), 90100. https://doi.org/10.2307/41165746

Elkington, J. (1998). Partnerships from cannibals with forks: The triple bottom line of 21 st-century business. Environmental quality management, 8(1), 37-51.

Hiotis, D., Biffl, D., Frank, A. (2020, 26 March). COVID-19 and Airlines- Start Planning recovery now. Retrieved from (https:/www.simon-kucher.com/en/blog/covid-19and-airlines-start-planning-recovery-now) on 21September 2020.

Mintz, S. M. (2011). Triple bottom line reporting for CPAs. The CPA journal, 81(12), 2633.

Patlins, A. (2017). Improvement of sustainability definition facilitating sustainable development of public transport system. Procedia engineering, 192, 659-664. https://doi.org/10.1016/j.proeng.2017.06.114

Richter, I. M. (2020). How Sustainable Development Affects the Aviation Industry. A Case

Study of the Lufthansa Group. GRIN Verlag.

Shover, S. (2010). Triple Bottom Line Analysis and Justifying Airport Infrastructure Projects.

Retrieved

from 
(http://www.intervistas.com/downloads/CAIR/articles/01_jan2010_b.pdf) on 18 September 2020.

Southwest Airlines Releases Fifth Integrated Annual Report on the Triple Bottom Line of Performance, People and Planet (2014, 17 June). Retrieved from (https://www.swamedia.com/releases/release-

9a169cfc3e1a4586854990f8602d826d-southwest-airlines-releases-fifth-annualintegrated-report-on-triple-bottom-line-of-performance-people-andplanet?query=our+low+fare+story) on 20 September, 2020.

The White Paper on National Green Aviation Policy. Ministry of Civil Aviation, The Government of India. (2020,19 February). Retrieved from (https://www.civilaviation.gov.in/sites/default/files/Whitepaper\%20on\%20National \%20Green\%20Aviation\%20Policy.pdf) on 20 September, 2020. 